\title{
The New Ubiquity
}

\section{By Peter J. Denning}

We are pleased to be launching a new Web site for Ubiquity (debuting in October 2010), marking a new editorial direction. Ubiquity is now a peer-reviewed online publication of ACM dedicated to the future of computing and the people who are creating it.

\section{How Ubiquity Started}

Ubiquity grew out of the ACM IT Profession Initiative, which was started by ACM Council in 1999. The initiative explored how ACM could respond in a world that was treating IT as a profession, and provide new services to support the development of the profession and the growth of its members. I was the initiative director and Joe DeBlasi (then the ACM executive director) was the initiative co-director.

The initiative started many conversations within ACM, leading eventually to new programs and structures including IT Deans group of the Computing Research Association (2002), ACM Queue (2003), Professional Development Centre (2005), Profession Board (2005), and job mobility study (2006).

The first outcome of the initiative was the creation of Ubiquity in 2000 as an online forum of commentary on the future development of an IT profession. ACM hired John Gehl as the executive editor of Ubiquity. We created an editorial board to advise John, and I was its chair.

In its first ten years, Ubiquity published 165 interviews and 415 commentaries.

\section{A Time of Transition}

In late 2007, John Gehl announced he would retire. The ACM Publication Board asked me to lead a conversion of Ubiquity to an all-volunteer publication, in line with ACM's approach to its other publications. 
All this comes to fruition now, with the launch of a new Ubiquity.

\section{The Changes to Ubiquity}

We are aligning all content with the new Ubiquity mission, which is to be a peerreviewed publication about the future of computing and the people who are creating it. We will publish several articles a month, about half commentaries and rest interviews. We will expand the editorial board to about two dozen editors. Each editor will be responsible for the publication of at least two high-quality items per year. Editors can write their own contributions (as contributing editors), invite contributions, process unsolicited contributions, or conduct interviews. In addition to appearing on this site, all Ubiquity articles are part of the ACM Digital Library. They are visible to all users of the library and are fully searchable. Interesting Ubiquity articles will be highlighted on CACM.acm.org so that all CACM readers can see them. Finally, we will launch a new feature, the symposium.

\section{The Ubiquity Symposium}

A symposium is a collection of analytic commentaries from multiple viewpoints about an issue. The content of a symposium will be released over a series of weeks. A symposium as a package will be visible on the Ubiquity table of contents and in the Digital Library. We expect two or three symposia annually. The first symposium is launching shortly on the topic "What is computation?" This topic goes to the heart of what the computing field is about.

\section{How You Can Participate}

I invite you to join us in one or more of these ways:

- Simply read and enjoy the articles and interviews.

- Sign up for the email notification service, which will tell you when new items have been published.

- Give your feedback to the authors and other readers through the blog.

- Apply to be a member of the editorial panel.

- Apply to organize a symposium. 
I look forward to your participation.

About the Author

Peter J. Denning is editor-in-chief of Ubiquity.

DOI: $10.1145 / 1865907.1865969$ 